\title{
Surgery in current therapy for infective endocarditis
}

This article was published in the following Dove Press journal:

Vascular Health and Risk Management

I5 April 201 I

Number of times this article has been viewed

\section{Stuart J Head' \\ M Mostafa Mokhles' \\ Ruben LJ Osnabrugge ${ }^{1,2}$ \\ Ad JJC Bogers' \\ A Pieter Kappetein' \\ 'Department of Cardio-Thoracic \\ Surgery, Erasmus University Medical \\ Center, Rotterdam, The Netherlands; \\ ${ }^{2}$ Department of Epidemiology, \\ Erasmus University Medical Center, \\ Rotterdam, The Netherlands}

Correspondence: AP Kappetein

Department of Cardiothoracic Surgery,

Room Bd 569, Erasmus University

Medical Center, PO Box 2040,

3000 CA Rotterdam,

The Netherlands

Tel $+31 \quad 107032150$

Fax +3I I0 7033993

Email a.kappetein@erasmusmc.nl

\begin{abstract}
The introduction of the Duke criteria and transesophageal echocardiography has improved early recognition of infective endocarditis but patients are still at high risk for severe morbidity or death. Whether an exclusively antibiotic regimen is superior to surgical intervention is subject to ongoing debate. Current guidelines indicate when surgery is the preferred treatment, but decisions are often based on physician preferences. Surgery has shown to decrease the risk of short-term mortality in patients who present with specific symptoms or microorganisms; nevertheless even then it often remains unclear when surgery should be performed. In this review we i) systematically reviewed the current literature comparing medical to surgical therapy to evaluate if surgery is the preferred option, ii) performed a meta-analysis of studies reporting propensity matched analyses, and iii), briefly summarized the current indications for surgery.

Keywords: endocarditis, surgery, antibiotics, review, meta-analysis, propensity analysis, mortality, complications
\end{abstract}

\section{Introduction}

Over the last decades infective endocarditis (IE) has been described extensively. ${ }^{1}$ This has identified risk factors, clinical features, and predictors of outcome, which led to the prescription of antibiotic prophylaxis during the perioperative stage of dental and cardiovascular surgery. ${ }^{2,3}$ Furthermore, the development of the Duke criteria as a diagnostic tool ${ }^{4}$ and the use of transesophageal echocardiography (TEE) have contributed significantly to early recognition. Despite these developments, outcomes nonetheless remain unsatisfactory. ${ }^{5-7}$ Peripheral or cerebrovascular embolisms and acute heart failure can cause a drastic decrease of the quality of life. Moreover, mortality rates continue to be as high as $50 \%$ in some studies.

The usage of an antibiotic regimen alone or in combination with surgical intervention is an ongoing debate. Studies investigating the best treatment have shown that surgery in combination with antibiotics is superior in some indications. ${ }^{8}$ The decision whether and when to treat endocarditis surgically often depends on local practice. Uniform recommendations are therefore difficult to make and an overall superiority of medical or surgical treatment is not yet established. In a propensity matched analysis, surgery seemed to be superior regarding in-hospital mortality, ${ }^{9,10}$ but at long-term follow-up, data suggests no benefit of surgical therapy compared to an exclusively medical regimen. ${ }^{11,12} \mathrm{~A}$ better outcome with surgical therapy was recently demonstrated in the largest reported matched cohorts. ${ }^{13}$ Still, these studies with propensity matched analysis do not produce unambiguous results. ${ }^{14}$ 
Timing of surgery is important. This issue has been extensively addressed and there is substantial evidence that early surgery can be performed safely, but no consensus exists on the optimal timing of valve replacement in the active phase of endocarditis. ${ }^{15,16}$ Waiting increases the risk of stroke or peripheral emboli while early surgery increases the risk of procedure-related complications, and longer antibiotic treatment can potentially avoid valve replacement.

It is clear that the optimal treatment for IE remains challenging. The ongoing ENDOVAL trial will be the first to report results of patients treated medically or surgically in a randomized fashion and can provide important data. ${ }^{17}$ Before these results will be presented treatment preferences are based on current data. This review systematically evaluates studies comparing medical to surgical therapy and discusses the timing of surgery.

\section{Current data}

\section{Systematic review: medical or surgical therapy?}

We performed a systematic review of studies reporting hospital mortality after medical and surgical treatment separately. The Medline database, web-of-science, and The Cochrane Library were consulted with search entries of "endocarditis" and "treatment or therapy or surgery or medical" and "outcome or survival or mortality or hazard ratio" in all possible combinations. Studies were excluded if they focused on a specific aspect of endocarditis, reported results of an exclusive patient cohort, or included less than 50 patients. Multiple studies overlapped in patient populations; only the study with the largest number of patients was included.

Forty eligible studies were identified. ${ }^{9-13,18-52}$ Data was pooled to obtain an overall view of the studied population; a total of 11,348 IE episodes were analyzed (Table 1, Figure 1). The largest study on endocarditis to date is from the International Collaboration on Endocarditis-Prospective Cohort Study (ICE-PCS), which was a prospective, multicenter, international registry with 2,781 patients from over 50 centers..$^{53}$ The combined data from the 40 studies had similar baseline characteristics for gender, PVE (\%), and periannular abscess (\%). Vegetations were visualized less in the combined data ( $87 \%$ compared to $70 \%$ in our data). The cause of endocarditis was also similar, although the number of Staphylococcus aureus infections was $21 \%$ in the combined series as to $31 \%$ in the registry, and viridans streptococci was identified in $20 \%$ compared to $17 \%$ in the ICE-PCS registry.
Table I Characteristics and outcome of IE in pooled analysis of 40 systematically included studies

\begin{tabular}{|c|c|c|}
\hline & $\begin{array}{l}\text { Episodes } \\
(\mathrm{N}=11,348)(\%)\end{array}$ & $\begin{array}{l}\text { Number of } \\
\text { studies (N) }\end{array}$ \\
\hline \multicolumn{3}{|l|}{ Characteristics } \\
\hline $\begin{array}{l}\text { Definite infective endocarditis } \\
\text { according to Duke criteria }\end{array}$ & $95.4 \%$ & (33) \\
\hline Males & $65.5 \%$ & $(39)$ \\
\hline $\begin{array}{l}\text { Prosthetic valve endocarditis } \\
\text { (all studies) }\end{array}$ & $20.2 \%$ & $(39)$ \\
\hline $\begin{array}{l}\text { Prosthetic valve endocarditis } \\
\text { (natural) }\end{array}$ & $21.9 \%$ & $(28)$ \\
\hline Surgery & $41.5 \%$ & $(40)$ \\
\hline \multicolumn{3}{|l|}{ Echocardiographic findings } \\
\hline Vegetations & $69.4 \%$ & $(32)$ \\
\hline Mobile vegetations & $51.7 \%$ & (7) \\
\hline New valve regurgitation & $47.6 \%$ & (7) \\
\hline Periannular complications & $16.2 \%$ & (4) \\
\hline Abscess & $12.7 \%$ & $(16)$ \\
\hline Perforation & $10.4 \%$ & $(8)$ \\
\hline Prosthetic valve dehiscence & $6.9 \%$ & $(12)$ \\
\hline \multicolumn{3}{|l|}{ Indications for surgery } \\
\hline Heart failure & $49.7 \%$ & $(17)$ \\
\hline Emboli & $17.8 \%$ & (16) \\
\hline Persistent infection & $18.8 \%$ & $(14)$ \\
\hline Abscess & $17.4 \%$ & $(12)$ \\
\hline Large vegetation & $21.5 \%$ & $(6)$ \\
\hline \multicolumn{3}{|l|}{ Complications } \\
\hline \multicolumn{3}{|l|}{ Emboli } \\
\hline Brain & $14.9 \%$ & $(14)$ \\
\hline Systemic/peripheral & $21.2 \%$ & $(21)$ \\
\hline Unspecified & $33.0 \%$ & (9) \\
\hline Heart failure & $34.1 \%$ & (34) \\
\hline Neurological events & $24.0 \%$ & (7) \\
\hline Stroke & $16.3 \%$ & $(6)$ \\
\hline In-hospital mortality & $19.2 \%$ & $(40)$ \\
\hline Surgical treatment & $15.8 \%$ & $(40)$ \\
\hline Medical treatment & $20.3 \%$ & $(40)$ \\
\hline
\end{tabular}

Notes: Prosthetic valve endocarditis "all studies" shows the incidence in all episodes. The "natural" occurrence of prosthetic valve endocarditis is the percentage in studies including all cases of endocarditis, and not studies specifically including prosthetic or native valve cases.

Results were remarkably similar; occurrences of stroke and non-stroke embolism were almost identical. Furthermore, heart failure was diagnosed in $34 \%$ compared to $32 \%$ in ICE-PCS, and in-hospital mortality was $19 \%$ versus $18 \%$ respectively.

One limitation of the ICE-PCS registry is that the indications for surgery were not reported. In our combined data of the 40 studies, surgery was performed in 4,714 episodes of endocarditis. Seventeen studies reported indications for surgery; heart failure (49.7\%) was the main reason, others were large vegetation on echocardiography $(21.5 \%)$, persistent infection (18.8\%), embolic complication (17.8\%), or abscess formation (17.4\%). Although it is likely that more complex 


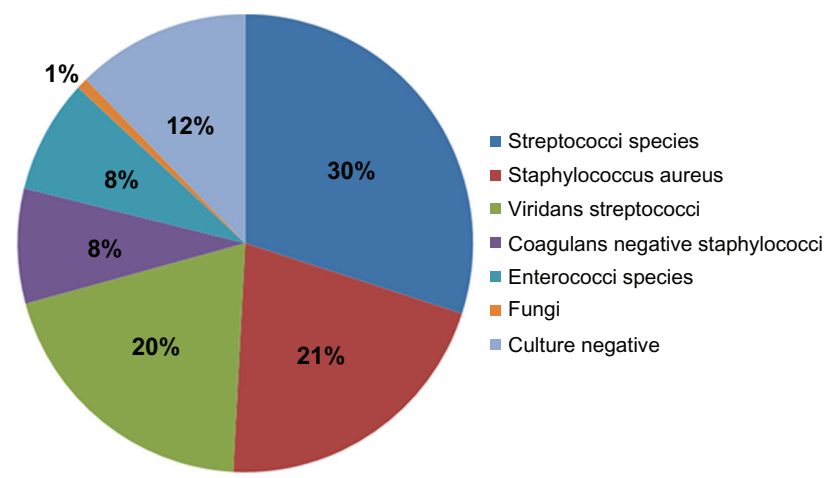

Figure I Causative microorganisms from pooled data of I I,348 IE episodes.

cases of endocarditis underwent surgery, the in-hospital mortality was significantly lower in these patients compared to those medically treated ( $15.8 \%$ versus $20.3 \%$ ). This could be explained by the fact that patients deemed too high risk for surgery due to their condition were treated non-surgically, thereby increasing the observed mortality in the medically treated patient cohort. As a result of treatment preferences, most studies include significant treatment bias and robust evidence-based conclusions are unavailable. Predicting which treatment is most beneficial for the individual patient remains challenging.

\section{Meta-analysis: propensity score studies}

A number of studies used propensity matching to compare medical to surgical therapy (Table 2) $\cdot{ }^{9-14,54}$ Studies that report in-hospital mortality either show results favoring surgical therapy over medical therapy or no statistical difference (Table 2). Combined data reveal an overall odds ratio of 0.47 (95\% confidence interval $[\mathrm{CI}]$ 0.38-0.58) supporting surgery. There is however a marked statistically significant heterogeneity $\left(\mathrm{I}^{2}=65 \%, P=0.005\right.$ (Figure 2$)$ ), meaning that there is excessive variation in the results.

\section{Bias}

Even though both the pooled and meta-analysis limit bias to some extent, included studies that report results after IE treatment are inherent to treatment and referral bias.

First of all, studies comparing medical to surgical treatment in a randomized fashion are not yet available. Baseline characteristics are therefore incomparable between groups. Even with propensity matched analyses, patients can only be matched considering the collected variables. Characteristics such as frailty are not available but can influence outcome. Other certain endocarditisspecific variables warrant surgical intervention and these variables will not be available in the medical group. These

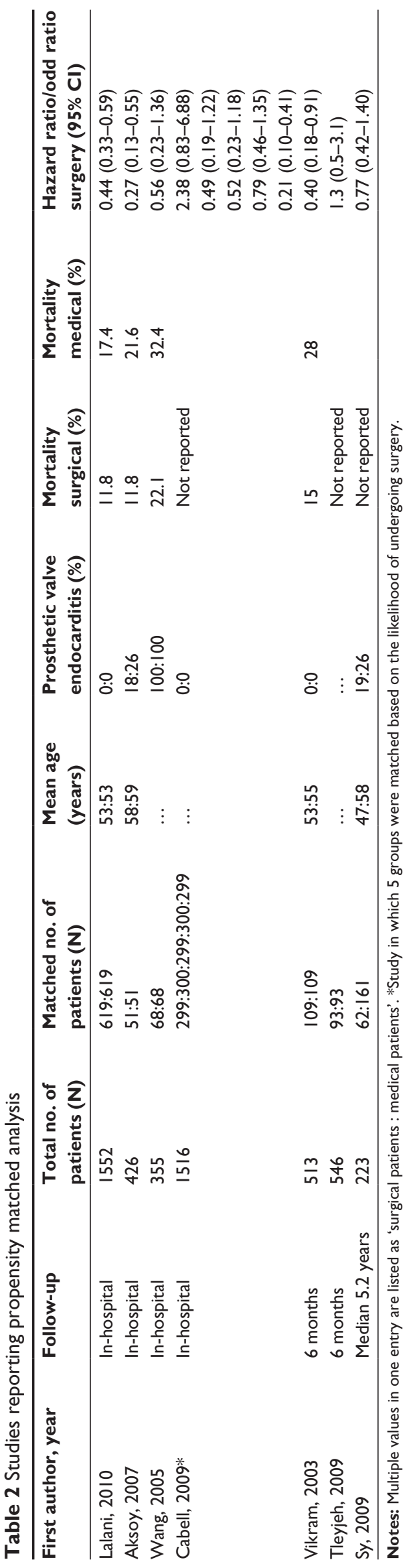




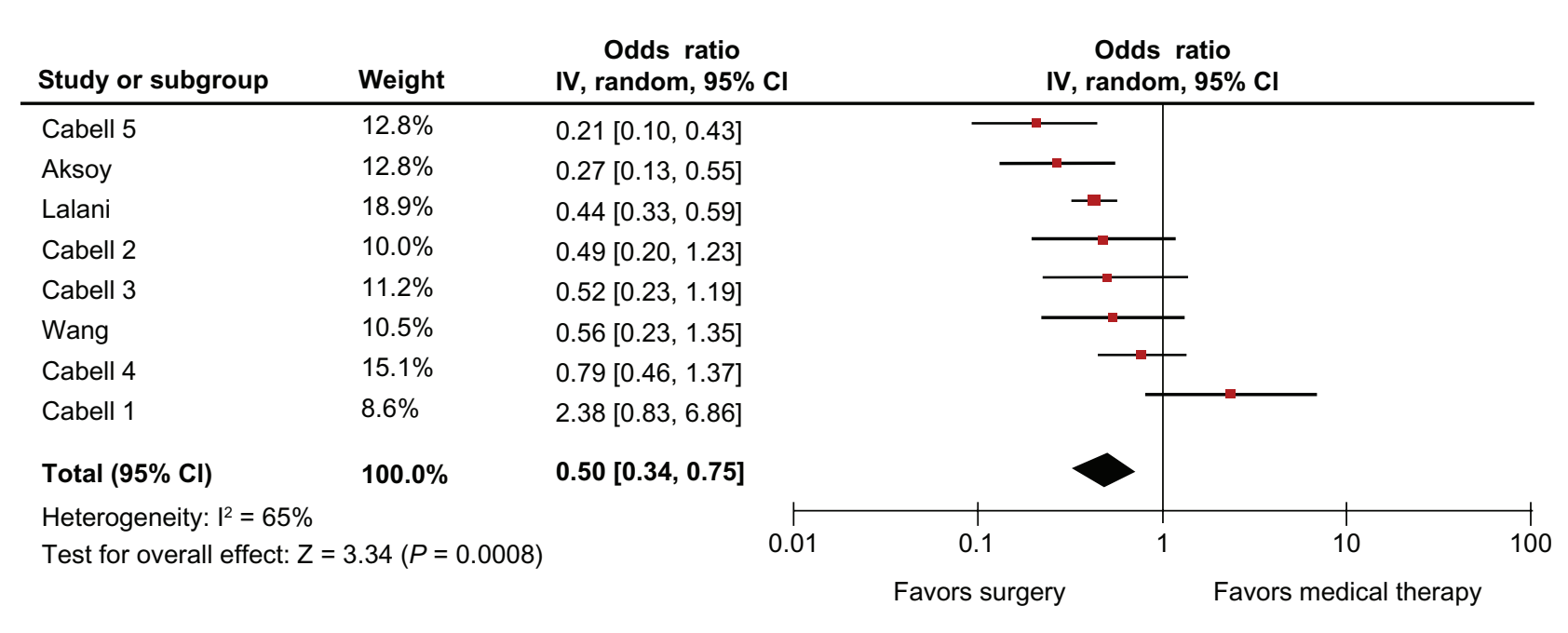

Figure 2 Meta-analysis of studies with propensity analysis.

variables can therefore not be matched, and while groups are allegedly 'matched', they often are not completely. A recent study demonstrated that adjustment for an additional survivor bias factor is needed, as it can significantly alter the results. ${ }^{55}$

Referral bias embodies another bias that is often present in the included studies. Patients from the ICE-PCS registry transferred to tertiary care centers more frequently underwent surgery and had higher rates of complications such as stroke, heart failure, or valve regurgitation. ${ }^{56}$ Results from certain centers can therefore be skewed in relation to other outcomes, and this should be kept in mind when evaluating these studies.

The studies included in the meta-analysis have previously been shown to be incomparable on multiple fronts.Inconsistent results are therefore likely to be not only dependable of the given treatment, but also due to used methods of data acquirement, co-morbidity definitions, the number of variables matched for, reporting of data, and statistical methods. ${ }^{57}$ Furthermore, the deliberate decision whether to treat medically or surgically is based on certain specific characteristics of the patient, and no study without or with propensity analysis can adjust for clinical judgment.

\section{Indications and timing for surgery}

In the pooled data, surgery was performed in $41.5 \%$ of IE cases. Apart from studies comparing medical to surgical therapy, extensive results of surgical series have been described. These studies have furthermore provided data on surgical indications and many of these indications have now been included in current guidelines. ${ }^{3,58,59}$

\section{Congestive heart failure}

Infective endocarditis often causes heart failure as a result of valve regurgitation, or sometimes because of valve obstruction or prosthetic valve dehiscence. Heart failure is a prognostic factor of impaired survival, independent of the causative microorganism or the status of infection. Many surgeons consider it as the main indication to perform surgery ${ }^{60}$

The timing of surgery depends on the progression of heart failure. Urgent surgery is needed if acute regurgitation of the aortic valve is present. A slower progressive presentation gives the opportunity to postpone surgery and await the effect of medical therapy.

\section{Periannular extension}

In native valve endocarditis periannular extension is present in $10 \%-40 \%$, but in prosthetic valve endocarditis (PVE) this is as high as $56 \%-100 \% .{ }^{61}$ Annulus involvement is associated with development of heart failure and increases mortality. Surgery is often indicated, especially when an abscess is present. The pooled data (Table 1) suggests that this is the case in almost $13 \%$, but a recent study focusing exclusively on surgical patients showed a rate of $38 \% .{ }^{62}$ Medical therapy is insufficient if an abscess has been detected on TEE, and guidelines therefore suggest that these patients should undergo surgery. ${ }^{3}$ If early surgical intervention is not performed an abscess can progress into fistulous cavities resulting in a mortality rate as high as $41 \%{ }^{63}$

Periannular extension is likely in case of persistent infection despite antibiotic therapy and surgery should be considered. An advantage of surgery over an antibiotic 
regimen is expressed in the completeness of therapy. Openheart surgery provides the opportunity to extensively remove infected tissue to prevent relapses.

\section{Emboli}

One of the major complications of IE is the development of systemic emboli in $22 \%-50 \%$ of the patients. ${ }^{64,65}$ Common affected sites are the lungs, spleen and peripheral arteries, but the most affected (65\%) is the central nervous system (CNS). ${ }^{65}$ Not only morbidity is high, but CNS emboli significantly increase the risk of mortality.

The prevention of such events is difficult, since the event itself can be the initial presentation of IE. These patients have a clear indication for urgent surgery. This however carries an increased risk of intracranial hemorrhage while waiting and medical therapy increases the risk of recurrent emboli. Current recommendations therefore suggest a 2-4 week antibiotic regimen before surgery can be performed safely. In patients who present with transient ischemic attacks or "silent" embolisms early surgery appears safe. No prospective studies have confirmed these findings, and more data is needed. ${ }^{66}$

Large vegetations on TEE are often of prognostic value of embolic events. Although there is not a uniform cut-off value, vegetations between $10-15 \mathrm{~mm}$ are an indication to perform urgent surgery.

\section{Persistent sepsis}

An ongoing infection despite antibiotic therapy is common with aggressive microorganisms, abscess formation, or large vegetations. Patients with persistent sepsis are at high risk to develop multi-organ failure and guidelines indicate that surgery is needed in these patients if cultures persist to be positive after 7 days of medical therapy. ${ }^{59,62}$ Some caution is however advised in patients that develop recurrent fever after an initially good response to antibiotics, because the fever could be explained by other reasons than the endocarditic valve. Surgery is only indicated if further diagnostics confirm persistent infection of the valve. ${ }^{61}$

\section{Microorganism}

A fungal cause often marks a complex case of IE. First of all, the diagnosis is delayed due to recurring negative blood cultures. Once IE is established medical therapy with antifungals is frequently unsatisfactory, resulting in the need for surgery in a large percentage of patients. Other indications for surgery are large vegetations and periannular extension that regularly complicate fungal IE.
Endocarditis caused by bacteria can be challenging as well, especially Staphylococcus aureus. ${ }^{67}$ These complicated infections with large vegetations and embolic manifestations result in an increased risk of mortality. If multi-resistant $S$ aureus is detected, surgery is the only conclusive therapy and is always indicated.

Several other micro-organisms such as Brucella, Q fever, Pseudomonas aeruginosa, and Staphylococcus lugdunensis indicate surgical intervention, but are rare in presentation. ${ }^{68-71}$

\section{Prosthetic Valve Endocarditis (PVE)}

In approximately $20 \%$ of IE a prosthetic valve is involved. ${ }^{72}$ A distinction is often made between early and late cases based on the time of diagnosis after initial surgery. The prognosis of PVE is worse than in native valve IE. ${ }^{72}$ Several studies have compared outcomes after medical and surgical therapy in PVE. ${ }^{14,22,25,33,38,51}$ A large cohort study of 367 prospectively followed patients showed that in-hospital mortality rates were similar: $23.4 \%$ in medical and $25 \%$ in surgical patients. ${ }^{14}$ Six months survival in a different study also showed no favorable result for surgery in 80 patients $(70 \%$ survival in medical and $73 \%$ in surgical patients). ${ }^{73}$ Surgery for PVE is often indicated, but is a troublesome procedure which is reflected in a high recurrent IE rate of up to $15 \%$. $^{74,75}$

\section{Right-sided endocarditis}

The incidence of right-sided IE represents less than $10 \%$ of all cases of IE. ${ }^{76,77}$ Right-sided endocarditis mainly occurs in patients with intravenous drug use, pacemaker or central venous lines, or congenital heart disease. The majority of cases involve the tricuspid valve, while isolated pulmonary valve endocarditis is rare. ${ }^{78}$

Isolated right-sided endocarditis has a favorable prognosis with low in-hospital mortality and the primary approach in these patients should therefore be conservative. Most cases respond to medical therapy and surgery is only necessary in a small minority of patients. ${ }^{79}$

The 10 and 20 year survival rate after surgery for isolated right-sided endocarditis has been reported to be $70 \%$ and $58 \%$ respectively, which is better than patients with left-sided IE. ${ }^{80}$

\section{Device-related endocarditis}

The use of pacemakers, defibrillators, and other implants has grown significantly over the last decades. As a result, endocarditis is more frequently associated with these devices. ${ }^{81}$ 
These types of endocarditis require excision of the infected device and complete eradication of the infection. Only thereafter can a new device be implanted. Percutaneous techniques allow the cardiologist to perform this procedure, and surgeon involvement is therefore not necessary.

\section{Risk stratification}

Due to the variability in the complexity of IE, the prognosis strongly depends on the individual patients' characteristics. Some patients benefit more from surgery than others, and to identify in which group of patients surgery can be performed safely and with an adequate result, a recent study developed a simplified risk scoring system including 13 variables. ${ }^{82}$ Although this model is noteworthy, one should be reminded that data is from the Society of Thoracic Surgeons (STS) database in which $>19,000$ patients surgically treated for IE were analyzed to relate baseline characteristics to 30-day outcomes. The database only includes general characteristics, but endocarditis-specific variables such as vegetation size, prosthetic valve endocarditis, or periannular extension are lacking. The model therefore is similar to the STS score, and is not specific for endocarditis. Also, this score is only based on surgical patients, and therefore it cannot be used to identify those who would benefit most.

Another recent study showed that additive and logarithmic EuroSCORE have a predictive value of 0.84 and 0.85 respectively, confirming that available risk models not specific for endocarditis can be sufficient to predict mortality. ${ }^{77}$

\section{Transcatheter aortic valve endocarditis}

The introduction of transcatheter aortic valve implantation (TAVI) to treat severe aortic stenosis could change the face of PVE. The occurrence of early PVE could be influenced by the difference between a sternotomy and access through the groin. The increased prevalence of paravalvular leakage raises concerns because of the associated risk of endocarditis. Little is known about the true incidence of endocarditis after TAVI; to date it has only been anecdotally described..$^{83,84}$ Follow-up has been short, and late PVE has therefore not yet been fully addressed. TAVI has recently shown positive results in the PARTNER (Placement of Aortic Transcatheter Valves) trial, ${ }^{85}$ and more randomized trials will start enrollment soon to broaden the indication to lower risk patients. ${ }^{86}$ Further data will contribute to the unknown prevalence of endocarditis after TAVI.

\section{New insights}

Late in 2011 the first randomized data from the ENDOVAL trial on surgical or medical treatment for IE will be available. The trial will only include high-risk patients with 1) periannular complications, 2) new onset aortic-ventricular block, 3) new onset severe valve regurgitation, 4) early-onset PVE, or 5) Staphylococcus aureus endocarditis. The trial will likely lead to treatment preferences for most endocarditis patients. Too high-risk patients with an EuroSCORE $>40 \%$ or an emergent/ urgent indication for surgery because of heart failure due to valvular insufficiency, fungal endocarditis, or septic shock are excluded. ${ }^{17}$ It is these patients that lead treatment bias when comparing studies from different centers. Some surgeons are willing to operate on the very high-risk patients, while others are reticent. To evaluate the need for surgery in high risk patients, another trial in high-risk patients is preferable. The ENDOVAL trial is the first trial assessing the use of early surgery in endocarditis, and could stimulate others to follow.

\section{Conclusions}

Endocarditis has been extensively described over the last decades and treatment with surgery is established for certain indications associated with improved survival. Surgical treatment of PVE carries quite a high mortality and requires close follow-up due to a continued postoperative risk. The selection of patients who benefit most from valve replacement is becoming more transparent, but treatment often remains biased because of surgeon preferences. A large number of ongoing studies and randomized trials will produce stronger evidence.

\section{Author disclosures}

The authors have no conflicts of interest to declare.

\section{References}

1. Cabell CH, Abrutyn E. Progress towards a global understanding of infective endocarditis. Early lessons from the International Collaboration on Endocarditis investigation. Infect Dis Clin North Am. 2002;16(2): 255-272.

2. Wilson W, Taubert KA, Gewitz M, et al. Prevention of infective endocarditis: guidelines from the American Heart Association: a guideline from the American Heart Association Rheumatic Fever, Endocarditis and Kawasaki Disease Committee, Council on Cardiovascular Disease in the Young, and the Council on Clinical Cardiology, Council on Cardiovascular Surgery and Anesthesia, and the Quality of Care and Outcomes Research Interdisciplinary Working Group. Circulation. 2007; 116(5):1736-1754.

3. Bonow RO, Carabello BA, Chatterjee K, et al. 2008 Focused update incorporated into the ACC/AHA 2006 guidelines for the management of patients with valvular heart disease: a report of the American College of Cardiology/American Heart Association Task Force on Practice Guidelines (Writing Committee to Revise the 1998 Guidelines for the Management of Patients With Valvular Heart Disease): endorsed by the Society of Cardiovascular Anesthesiologists, Society for Cardiovascular Angiography and Interventions, and the Society of Thoracic Surgeons. Circulation. 2008;118(15):e523-e661. 
4. Durack DT, Lukes AS, Bright DK. New criteria for diagnosis of infective endocarditis: utilization of specific echocardiographic findings. Duke Endocarditis Service. Am J Med. 1994;96(3):200-209.

5. Heiro M, Helenius H, Mäkilä S, et al. Infective endocarditis in a Finnish teaching hospital: a study on 326 episodes treated during 1980-2004. Heart. 2006;92(10):1457-1462.

6. Durante-Mangoni E, Bradley S, Selton-Suty C, et al. Current features of infective endocarditis in elderly patients: results of the International Collaboration on Endocarditis Prospective Cohort Study. Arch Intern Med. 2008;168(19):2095-2103.

7. Mansur AJ, Dal Bó CM, Fukushima JT, Issa VS, Grinberg M, Pomerantzeff PM. Relapses, recurrences, valve replacements, and mortality during the longterm follow-up after infective endocarditis. Am Heart J. 2001;141(1):78-86.

8. Yu VL, Fang GD, Keys TF, et al. Prosthetic valve endocarditis: superiority of surgical valve replacement versus medical therapy alone. Ann Thorac Surg. 1994;58(4):1073-1077.

9. Cabell CH, Abrutyn E, Fowler VG Jr, et al. Use of surgery in patients with native valve infective endocarditis: results from the International Collaboration on Endocarditis Merged Database. Am Heart J.2005;150(5):1092-1098.

10. Aksoy O, Sexton DJ, Wang A, et al. Early Surgery in Patients with Infective Endocarditis: A Propensity Score Analysis. Clin Infect Dis. 2007;44(3):364-372.

11. Tleyjeh IM, Ghomrawi HM, Steckelberg JM, et al. The impact of valve surgery on 6-month mortality in left-sided infective endocarditis. Circulation. 2007;115(13):1721-1728.

12. Sy RW, Bannon PG, Bayfield MS, Brown C, Kritharides L. Survivor treatment selection bias and outcomes research: a case study of surgery in infective endocarditis. Circ Cardiovasc Qual Outcomes. 2009;2(5): $469-474$.

13. Lalani T, Cabell CH, Benjamin DK, et al. Analysis of the impact of early surgery on in-hospital mortality of native valve endocarditis: use of propensity score and instrumental variable methods to adjust for treatment-selection bias. Circulation. 2010;121(8): 1005-1013.

14. Wang A, Pappas P, Anstrom KJ, et al. The use and effect of surgical therapy for prosthetic valve infective endocarditis: a propensity analysis of a multicenter, international cohort. Am Heart J. 2005;150(5): 1086-1091.

15. Bogers AJ, van Vreeswijk H, Verbaan CJ, et al. Early surgery for active infective endocarditis improves early and late results. Thorac Cardiovasc Surg. 1991;39(5):284-288.

16. Thuny F, Beurtheret S, Mancini J, et al. The timing of surgery influence mortality and morbidity in adults with severe complicated infective endocarditis: a propensity analysis. Eur Heart J. 2009; doi:10.1093/ eurheartj/ehp089.

17. San Román JA, López J, Revilla A, et al. Rationale, design, and methods for the early surgery in infective endocarditis study (ENDOVAL 1): a multicenter, prospective, randomized trial comparing the state-of-the-art therapeutic strategy versus early surgery strategy in infective endocarditis. Am Heart J. 2008;156(3): 431-436.

18. Tornos MP, Olona M, Permanyer-Miralda G, Almirante B, Evangelista A, Soler-Soler J. Is the clinical spectrum and prognosis of native valve infective endocarditis in non-addicts changing? Eur Heart J. 1995; 16(11):1686-1691.

19. Schulz R, Werner GS, Fuchs JB, et al. Clinical outcome and echocardiographic findings of native and prosthetic valve endocarditis in the 1990's. Eur Heart J. 1996;17(2):281-288.

20. Sandre RM, Shafran SD. Infective endocarditis: review of 135 cases over 9 years. Clin Infect Dis. 1996;22(2):276-286.

21. Olaison L, Hogevik H, Myken P, Oden A, Alestig K. Early surgery in infective endocarditis. QJM. 1996;89(4):267-278.

22. Tornos $\mathrm{P}$, Almirante B, Olona $\mathrm{M}$, et al. Clinical outcome and long-term prognosis of late prosthetic valve endocarditis: a 20-year experience. Clin Infect Dis. 1997;24(3):381-386.
23. Hricak V, Kovacik J, Marx P, et al. Etiology and risk factors of 180 cases of native valve endocarditis. Report from a 5-year national prospective survey in Slovak Republic. Diagn Microbiol Infect Dis. 1998;31(3): $431-435$.

24. Castillo JC, Anguita MP, Ramírez A, et al. Long term outcome of infective endocarditis in patients who were not drug addicts: a 10 year study. Heart. 2000;83(5):525-530.

25. Gordon SM, Serkey JM, Longworth DL, Lytle BW, Cosgrove DM 3rd. Early onset prosthetic valve endocarditis: the Cleveland Clinic experience 1992-1997. Ann Thorac Surg. 2000;69(5):1388-1392.

26. Bishara J, Leibovici L, Gartman-Israel D, et al. Long-term outcome of infective endocarditis: the impact of early surgical intervention. Clin Infect Dis. 2001;33(10):1636-1643.

27. Wallace SM, Walton BI, Kharbanda RK, Hardy R, Wilson AP, Swanton RH. Mortality from infective endocarditis: clinical predictors of outcome. Heart. 2002;88(1):53-60.

28. Mouly S, Ruimy R, Launay R, et al. The changing clinical aspects of infective endocarditis: descriptive review of 90 episodes in a French teaching hospital and risk factors for death. J Infect. 2002;45(4): 246-256.

29. Hoen B, Alla F, Selton-Suty C, et al. Changing Profile of Infective Endocarditis: Results of a 1-Year Survey in France. JAMA. 2002;288(1): 75-81.

30. Pachirat O, Chetchotisakd P, Klungboonkrong V, Taweesangsuksakul P, Tantisirin C, Loapiboon M. Infective endocarditis: prevalence, characteristics and mortality in Khon Kaen, 1990-1999. J Med Adoc Thai. 2002;85(1):1-10.

31. Di Salvo G, Thuny F, Rosenberg V, et al. Endocarditis in the elderly: clinical, echocardiographic, and prognostic features. Eur Heart J. 2003;24(17):1576-1583.

32. Ako J, Ikari Y, Hatori M, Hara K, Ouchi Y. Changing spectrum of infective endocarditis: review of 194 episodes over 20 years. Circ J. 2003;67(1):3-7.

33. Akowuah EF, Davies W, Oliver S, et al. Prosthetic valve endocarditis: early and late outcome following medical or surgical treatment. Heart. 2003;89(3):269-272.

34. Krcmery V, Gogová M, Ondrusová A, et al. Etiology and risk factors of 339 cases of infective endocarditis: report from a 10-year national prospective survey in the SLovak Republic. J Chemother. 2003; 15(6):579-583.

35. Mourvillier B, Trouillet JL, Timsit JF, et al. Infective endocarditis in the intensive care unit: clinical spectrum and prognostic factors in 228 consecutive patients. Intensive Care Med. 2004;30(11): 2046-2052.

36. Zamorano J, de Isla LP, Moura L, et al. Impact of echocardiography in the short- and long-term prognosis of patients with infective endocarditis and negative blood cultures. J Heart Valve Dis. 2004;13(6): 997-1004.

37. Cecchi E, Forno D, Imazio M, et al. New trends in the epidemiological and clinical features of infective endocarditis: results of a multicenter prospective study. Ital Heart J. 2004;5(4):249-256.

38. Habib G, Tribouilloy C, Thuny F, et al. Prosthetic valve endocarditis: who needs surgery? A multicentre study of 104 cases. Heart. 2005; 91(7):954-959.

39. Garg N, Kandpal B, Garg N, et al. Characteristics of infective endocarditis in a developing country-clinical profile and outcome in 192 Indian patients, 1992-2001. Int J Cardiol. 2005;98(2):253-260.

40. Tornos P, Iung B, Permanyer-Miralda G, et al. Infective endocarditis in Europe: lessons from the Euro heart survey. Heart. 2005;91(5): 571-575.

41. Ferreiros E, Nacinovich F, Casabé JH, et al. Epidemiologic, clinical, and microbiologic profile of infective endocarditis in Argentina: a national survey. The Endocarditis Infecciosa en la República Argentina-2 (EIRA-2) Study. Am Heart J. 2006;151(2):545-552.

42. Leblebicioglu H, Yilmaz H, Tasova Y, et al. Characteristics and analysis of risk factors for mortality in infective endocarditis. Eur J Epidemiol. 2006;21(1):25-31. 
43. Abramczuk E, Hryniewiecki T, Stepińska J. Influence of pathogenetic factors on prognosis in patients with native valve infective endocarditis. Kardiol Pol. 2006;64(7):675-681.

44. Slater MS, Komanapalli CB, Tripathy U, Ravichandran PS, Ungerleider RM. Treatment of endocarditis: a decade of experience. Ann Thorac Surg. 2007;83(6):2074-2079.

45. Delahaye F, Alla F, Béguinot I, et al. In-hospital mortality of infective endocarditis: prognostic factors and evolution over an 8-year period. Scand J Infect Dis. 2007;39(10):849-857.

46. Heiro M, Helenius H, Hurme S, et al. Short-term and one-year outcome of infective endocarditis in adult patients treated in a Finnish teaching hospital during 1980-2004. BMC Infect Dis. 2007;7:78.

47. Krecki R, Drozdz J, Ibata G, et al. Clinical profile, prognosis and treatment of patients with infective endocarditis; a 14-year follow-up study. Pol Arch Med Wewn. 2007;117(11-12):512-520.

48. Trabelsi I, Rekik S, Znazen A, et al. Native valve infective endocarditis in a tertiary care center in a developing country (Tunisia). Am J Cardiol. 2008;102(9):1247-1251.

49. Pazdernik M, Baddour LM, Pelouch R. Infective endocarditis in the Czech Republic: eight years of experience at one of the country's largest medical centers. J Heart Valve Dis. 2009;18(4):395-400.

50. Nunes MC, Gelape CL, Ferrari TC. Profile of infective endocarditis at a tertiary care center in Brazil during a seven-year period: prognostic factors and in-hospital outcome. Int J Infect Dis. 2010;14(5): e394-e398.

51. Alonso-Valle H, Fariñas-Alvarez C, García-Palomo JD, et al. Clinical course and predictors of death in prosthetic valve endocarditis over a 20-year period. J Thorac Cardiovasc Surg. 2010;139(4): 887-893.

52. López J, Revilla A, Vilacosta I, et al. Age-dependent profile of leftsided infective endocarditis: a 3-center experience. Circulation. 2010; 121(7):892-897.

53. Murdoch DR, Corey GR, Hoen B, et al. Clinical presentation, etiology, and outcome of infective endocarditis in the 21st century: the International Collaboration on Endocarditis-Prospective Cohort Study. Arch Intern Med. 2009;169(5):463-473.

54. Vikram HR, Buenconsejo J, Hasbun R, Quagliarello VJ. Impact of valve surgery on 6-month mortality in adults with complicated, left-sided native valve endocarditis: a propensity analysis. JAMA. 2003;290(24):3207-3214

55. Tleyjeh IM, Ghomrawi HM, Steckelberg JM, et al. Conclusion about the association between valve surgery and mortality in an infective endocarditis cohort changed after adjusting for survivor bias. J Clin Epidemiol. 2010;63(2):130-135.

56. Kanafani ZA, Kanj SS, Cabell CH, et al. Revisiting the effect of referral bias on the clinical spectrum of infective endocarditis in adults. Eur $J$ Clin Microbiol Infect Dis. 2010;29(10):1203-1210.

57. Tleyjeh IM, Kashour T, Zimmerman V, Steckelberg JM, Wilson WR, Baddour LM. The role of valve surgery in infective endocarditis management: a systematic review of observational studies that included propensity score analysis. Am Heart J. 2008;156(5): 901-909.

58. Habib G, Hoen B, Tornos P, et al. Guidelines on the prevention, diagnosis, and treatment of infective endocarditis (new version 2009): the Task Force on the Prevention, Diagnosis, and Treatment of Infective Endocarditis of the European Society of Cardiology (ESC). Eur Heart J. 2009;30(19):2369-2413.

59. Baddour LM, Wilson WR, Bayer AS, et al. Infective endocarditis: diagnosis, antimicrobial therapy, and management of complications: a statement for healthcare professionals from the Committee on Rheumatic Fever, Endocarditis, and Kawasaki Disease, Council on Cardiovascular Disease in the Young, and the Councils on Clinical Cardiology, Stroke, and Cardiovascular Surgery and Anesthesia, American Heart Association: endorsed by the Infectious Diseases Society of America. Circulation. 2005;111(23):e395-e434.
60. Revilla A, López J, Villacosta I, et al. Clinical and prognostic profile of patients with infective endocarditis who need urgent surgery. Eur Heart J. 2007;28(1):65-71.

61. Prendergast BD, Tornos P. Surgery for infective endocarditis: who and when? Circulation. 2010;121(9):1141-1152.

62. Klieverik LM, Yacoub MH, Edwards S, et al. Surgical treatment of active native aortic valve endocarditis with allografts and mechanical prostheses. Ann Thorac Surg. 2009;88(6):1814-1821.

63. Anguera I, Miro JM, Vilacosta I, et al. Aorto-cavitary fistulous tract formation in infective endocarditis: clinical and echocardiographic features of 76 cases and risk factors for mortality. Eur Heart J. 2005; 26(3):288-297.

64. Thuny F, Di Salvo G, Belliard O, et al. Risk of embolism and death in infective endocarditis: prognostic value of echocardiography: a prospective multicenter. Circulation. 2005;112(1):69-75.

65. Heiro M, Nikoskelainen J, Engblom E, Kotilainen E, Marttila R, Kotilainen P. Neurologic manifestations of infective endocarditis: a 17 year experience in a teaching hospital in Finland. Arch Intern Med. 2000;160(18):2781-2787.

66. Derex L, Bonnefoy E, Delahaye F. Impact of stroke on therapeutic decision making in infective endocarditis. J Neurol. 2010;257:315-321.

67. Remadi JP, Habib G, Nadji G, et al. Predictors of death and impact of surgery in Staphylococcus aureus infective endocarditis. Ann Thorac Surg. 2007;83(4):1295-1302.

68. Morpeth S, Murdoch D, Cabell CH, et al. Non-HACEK gram-negative bacillus endocarditis. Ann Intern Med. 2007;147(12):829-835.

69. Raoult D, Marrie T. Q Fever. Clin Infect Dis. 1995;20(3):489-495.

70. Jacobs F, Abramowicz D, Vereerstraeten P, Le Clerc JL, Zech F, Thys JP. Brucella endocarditis: the role of combined medical and surgical treatment. Rev Infect Dis. 1990;12(5):740-744.

71. Anguera I, Del Río A, Miró JM, et al. Staphylococcus lugdunensis infective endocarditis: description of 10 cases and analysis of native valve, prosthetic valve, and pacemaker lead endocarditis clinical profiles. Heart. 2005;91(2):e10.

72. Wang A, Athan E, Pappas PA, et al. Contemporary clinical profile and outcome of prosthetic valve endocarditis. JAMA. 2007;297(12): $1354-1361$.

73. Hill EE, Herregods MC, Vanderschueren S, Claus P, Peetermans WE, Herijgers P. Management of prosthetic valve infective endocarditis. Am J Cardiol. 2008;101(8):1174-1178.

74. Lytle BW, Priest BP, Taylor PC, et al. Surgical treatment of prosthetic valve endocarditis. J Thorac Cardiovasc Surg. 1996;111(1):198-207.

75. Pansini S, di Summa M, Patane F, Forsenatti PG, Serra M, Del Ponte S. Risk of recurrence after reoperation for prosthetic valve endocarditis. J Heart Valve Dis. 1997;6(1):84-87.

76. Mylonakis E, Calderwood SB. Infective endocarditis in adults. $N$ Engl J Med. 2001;345(18):1318-1330.

77. Mokhles MM, Ciampichetti I, Head SJ, Takkenberg JJM, Bogers AJJC. Survival of surgically treated infective endocarditis: a comparison with the general Dutch population. Ann Thorac Surg. 2011; doi:10.1016/j. athoracsur. 2011.02.007.

78. Nishida K, Fukuyama O, Nakamura DS. Pulmonary valve endocarditis caused by right ventricular outflow obstruction in association with sinus of valsalva aneurysm: a case report. J Cardiothorac Surg. 2008;3:46.

79. Hecht SR, Berger M. Right-sided endocarditis in intravenous drug users. Prognostic features in 102 episodes. Ann Intern Med. 1992;117(7): 560-566.

80. Musci M, Siniawski H, Pasic M, Grauhan O, Weng Y, Meyer R, et al. Surgical treatment of right-sided active infective endocarditis with or without involvement of the left heart: 20-year single center experience. Eur J Cardiothor Surg. 2007;32:118-125.

81. Baddour LM, Bettmann MA, Bolger AF, et al. Nonvalvular cardiovascular device related infections. Circulation. 2003;108(16):2015-2031.

82. Gaca JG, Sheng S, Daneshmand MA, et al. Outcomes for endocarditis surgery in North America: a simplified risk scoring system. J Thorac Cardiovasc Surg. 2011;141(1):98-106. 
83. Piazza N, Marra S, Webb J, et al. Two cases of aneurysm of the anterior mitral valve leaflet associated with transcatheter aortic valve endocarditis: a mere coincidence? J Thorac Cardiovasc Surg. 2010; 140(3):e36-e38.

84. Head SJ, Dewey TM, Mack MJ. Fungal endocarditis after transfemoral aortic valve implantation. Catheter Cardiovasc Interv. 2011; doi: $10.1002 / \mathrm{ccd} .23038$.
85. Leon MB, Smith CR, Mack M, et al. Transcatheter aortic-valve implantation for aortic stenosis in patients who cannot undergo surgery. N Engl J Med. 2010;363(17):1597-1607.

86. Head SJ, Kappetein AP. Transcatheter aortic valve implantation after PARTNER: what is up next? Euro Intervention. 2010;6(5):560-561.

\section{Publish your work in this journal}

Vascular Health and Risk Management is an international, peerreviewed journal of therapeutics and risk management, focusing on concise rapid reporting of clinical studies on the processes involved in the maintenance of vascular health; the monitoring, prevention and treatment of vascular disease and its sequelae; and the involvement of metabolic disorders, particularly diabetes. This journal is indexed on PubMed Central and MedLine. The manuscript management system is completely online and includes a very quick and fair peer-review system, which is all easy to use. Visit http://www.dovepress.com/ testimonials.php to read real quotes from published authors.

Submit your manuscript here: http://www.dovepress.com/vascular-health-and-risk-management-journal 